\title{
The I in autism: severity and social functioning in autism are related to self- processing
}

Karri Gillespie-Smith, Carrie Ballantyne, Holly P. Branigan, David J. Turk and Sheila J. Cunningham

This is the peer reviewed version of the following article:

Gillespie-Smith, K., et al. 2017. The I in autism: Severity and social functioning in autism are related to selfprocessing. British Journal of Developmental Psychology.

which has been published in final form at doi: http://dx.doi.org/10.1111/bjdp.12219

This article may be used for non-commercial purposes in accordance with Wiley Terms and Conditions for SelfArchiving. 
Manuscript accepted in British Journal of Developmental Psychology 22

October 2017

Title:- The I in Autism: Severity and social functioning in Autism is related to self-processing

Karri Gillespie-Smith ${ }^{\mathrm{a}}$, Carrie Ballantyne ${ }^{\mathrm{a}}$, Holly P. Branigan ${ }^{\mathrm{b}}$, David J. Turk ${ }^{\mathrm{c}} \&$ Sheila Cunningham ${ }^{\mathrm{d}}$

a. Division of Psychology, University of West of Scotland

b. Department of Psychology, Edinburgh University

c. School of Experimental Psychology, Bristol University

d. Division of Psychology, Abertay University

Corresponding Author:

Karri Gillespie-Smith, Division of Psychology, School of Media, Culture and Society, University of West of Scotland, Paisley Campus, PA1 2BE email: Karri.GillespieSmith@uws.ac.uk. Tel: +44 (0) 1418494020.

Acknowledgements: We thank the children, parents and teachers who participated in this study, and Jade Anderson, Kate Cotton, Rachel Gibson and Sara-Jo Kane for data collection and coding assistance. 


\title{
Title: The I in Autism: Severity and social functioning in Autism is related to
}

\section{self-processing bias}

\begin{abstract}
$\underline{\text { Abstract }}$
It is well established that children with Autism Spectrum Disorder (ASD) show impaired understanding of others and deficits within social functioning. However, it is still unknown whether self-processing is related to these impairments and to what extent self impacts social functioning and communication. Using an ownership paradigm, we show that children with ASD and chronological- and verbal-agematched typically developing (TD) children do show the self referential effect in memory. In addition, the self bias was dependent on symptom severity and sociocommunicative ability. Children with milder ASD symptoms were more likely to have a high self-bias, consistent with a low attention to others relative to self. In contrast, severe ASD symptoms were associated with reduced self-bias, consistent with an 'absent self' hypothesis. These findings indicate that deficits in selfprocessing may be related to impairments in social cognition for those on the lower end of the autism spectrum.
\end{abstract}

\section{Keywords}

Self; Ownership; Autism; ASD; Individual Differences 


\section{Introduction}

Autism Spectrum Disorder (ASD) is a developmental disorder diagnosed by a cluster of symptoms and behaviors within two criterion domains: social communication and restricted or repetitive behaviors (American Psychiatric Association, 2013). Impairments in the two diagnostic domains manifest in varying degrees and are dependent on developmental age and ability, resulting in a heterogeneous group (Frith, 2003). A central feature of ASD is a social processing difficulty that impacts on reciprocal communication, understanding, and behavior (American Psychiatric Association, 2013). To date, research into social processing has largely focused on how individuals with ASD process information about other people (e.g., theory of mind, emotion recognition, the empathizing-systemizing balance, Baron-Cohen, et al., 1999; Leekam \& Perner, 1991; Philip et al., 2010). However, a growing body of research speaks to a second critical area of social cognition: self-processing.

It has been argued that the self is at the heart of social cognition, with an understanding of self as a basis for the understanding of other people (i.e., simulation theory; see Goldman, 2006). Following this logic, an impaired self-concept may be anchored within some of the socio-communicative impairments in ASD (Frith, 2003; Frith \& Happe, 1999; Lombardo, Barnes, Wheelwright, \& Baron-Cohen, 2007; Mundy, 2003). Indeed, the term 'autism' is derived from the Greek word for self, reflecting the egocentricity historically associated with ASD (Asperger, 1944). While this egocentrism may actually arise as a by-product of inattention to other people (see Hobson, 1984), there is some research suggesting that self-processing itself is atypical in ASD, leading to the 'absent-self' hypothesis (Frith \& Happé, 1999; Frith, 2003). For example, individuals with ASD display less self-conscious emotion (Kasari, 
Sigman, Baumgartner, \& Stipek, 2006; Heerey, Keltner, \& Capps, 2003), show a reduction in autobiographical memory (relative to semantic memory - Crane \& Goddard, 2008; Millward Powell, Messer, \& Jordon, 2000), and have atypical neural responses to self-referent stimuli (e.g., failing to show the ventromedial prefrontal activation that distinguishes self from other in neurotypical adults - Lombardo, Chakrabarti, Bullmore, Sadek, Pasco, et al., 2010). A deficit in self-processing may therefore be a causal part of the social difficulties associated with ASD, so it is important to have a detailed understanding of how self-development in children with ASD may differ from that of typically developing children.

Interestingly, the early development of self-recognition progresses at a similar rate in children with ASD and those who are typically-developing, with both groups meeting the milestone of mirror self-recognition at around the chronological age of 18 months (Dawson \& McKissick 1984; Neuman \& Hill 1978; Spiker \& Ricks 1984). Intact self-recognition is further evidenced by reports of both typical neural activation on perception of self-images (Uddin et al., 2008), and typical attention allocation to self-images (Gillespie-Smith, Doherty-Sneddon, Hancock \& Riby 2014). These patterns suggest that individuals with ASD do show physical self-recognition (Povinelli, 2001).

In contrast, other developmental milestones of self-processing show differences between children with ASD and typically developing children. For example, children with ASD show reduced spontaneous personal pronoun use relative to other children of similar verbal abilities (Lee, Hobson, \& Chiat, 1994), indicative of a difficulty in explicitly differentiating themselves from others (Lind \& Bowler, 2009). Neurological evidence suggests that a psychological self-concept is delayed or impaired in autism (Bird, et al. 2010; Fitzgerald, Angstadt, Jelsone, Nathan \& Phan, 
2006; Lombardo, Chakrabarti, Bullmore, Sadek, \& Pasco, 2010; Silani, et al. 2008). Further to this, Lombardo et al. (2010) found that when participants were asked to mentalize about themselves or another person (the Queen); there were specific disruptions in adults with ASD within the neural networks involved in processing self-information. Specifically, changes (i.e. differences between baseline and activity) in the ventromedial prefrontal activation that typify self-referential cognition (Kelley, Macrae, Wyland, Caglar, Inati, \& Heatherton, 2002; Moran, Macrae, Heatherton, Wyland \& Kelley, 2006) were present in neurotypical participants but absent in those with ASD. In addition, those with ASD also showed atypical middle cingulate activation in response to other-mentalizing (relative to self-mentalizing). This evidence suggests that while physical self-recognition is unimpaired in ASD, psychological self-processing is disrupted (Dunphy-Lelii \& Wellman, 2012).

The distinction between physical and psychological self-knowledge is important because it may explain an area of mixed findings regarding self-processing biases in autism research. The study of self-processing in neurotypical individuals has revealed that self-related material activates processing biases to a greater degree than non-self-related information. For example, information relating to the self automatically attracts attention, is perceived more quickly, increases physiological arousal, and results in rich, episodic encoding (Bargh, 1982; Conway \& Dewhurst, 1995; Klein \& Loftus, 1988; Sui, He, \& Humphreys, 2012; Turk, Cunningham, \& Macrae, 2008; Turk, van Bussel, Waiter, \& Macrae, 2011; Turk, van Bussel, Brebner, Toma, Krigolson \& Handy, 2011). This is exemplified by the 'self-reference effect' (SRE) on memory, the memorial advantage for material encoded with reference to self over information encoded with reference to other people or at a semantic level (Rogers, Kuiper, \& Kirker, 1977; Symons \& Johnson, 1997). In typically-developing 
children and adults, the SRE is a remarkably robust effect, with meta-analysis confirming that across multiple studies, self-referenced information consistently enjoys a memory advantage (Symons \& Jonson, 1997).

Despite the general reliability of SREs, the evidence for whether they arise in ASD is somewhat equivocal (for a review please see Lind, 2010). Toichi, Kamio, Okada, Sakihama, Youngstrom, Findling, and Yamamoto (2002) used a standard trait judgment task in which participants were asked whether they or another individual possess a series of character traits. This paradigm generally elicits better memory for self-referent traits than other-referent traits. Toichi et al. observed no SRE in high functioning adults with ASD (evidenced by the group not showing a self-advantage during the self versus semantic level of processing conditions), a pattern the authors attributed to a lack of self-conscious awareness. In contrast, based on the same trait judgment paradigm, Lombardo, Barnes, Wheelwright and Baron-Cohen (2007) found that high functioning participants with ASD $(n=30)$ did show an SRE when asked to judge the number of syllables in a trait adjective or whether a trait applies to themselves, a best friend or Harry Potter (fictional character). All groups (including those with ASD) remembered more words learned during the Self condition than any other (Self $>$ Best Friend $>$ Harry Potter $>$ Syllable), although the magnitude of the selfreference effect was smaller in the ASD group.

Studies involving children with ASD have failed to demonstrate clear selfreferential encoding advantages using the trait judgment task. Henderson et al. (2009) asked children (mean age $=12.5$ years) to read a list of adjectives, deciding whether the adjective either described them (self), described Harry Potter, or was over a specified word length (featural). While a control group of neurotypical children and a group of learning impaired children showed a clear SRE, the high functioning 
children with ASD $(n=31)$ did not. In a similar vein to Lombardo et al., the ASD group showed a depth of processing effect (Harry Potter/Self $>$ Featural) but not a self-reference effect (Self=Harry Potter). In addition, the authors report a negative correlation between symptom severity in the ASD group and the SRE, suggesting that children with more severe ASD characteristics showed the least SRE. A more recent study by Burrows, Usher, Mundy and Henderson (2017) replicated the original Henderson et al., paradigm, finding a reduced SRE in the ASD group compared to the TD group. These studies tentatively suggest that self-referential encoding biases in ASD groups can occur, but may be further complicated by participant group characteristics such as ASD severity levels and symptomology.

An important reason for the lack of both quantity and clarity of data concerning the SRE in autism may be that the trait judgment paradigm is ill-suited to studying the self-processing system in this population. Trait evaluation requires an ability to consider the abstract psychological self, so if there are impairments in understanding self or others at this level, this may undermine memory performance. It is clear that alternative paradigms must be applied if we are to better comprehend the nature of self-construct in ASD, which are not reliant on an abstract understanding of self.

Interestingly, research employing concrete, non-evaluative encoding tasks (e.g., linking stimuli to self through ownership) has elicited reliable SREs in both adults (e.g., Cunningham, Turk, MacDonald, \& Macrae 2008; Gutchess, Sokal, Coleman, Gotthilf, Grewal, \& Rosa, 2015; Van den Bos, Cunningham, \& Turk, 2010) and children (Cunningham, Brebner, Quinn \& Turk, 2014; Cunningham, Vergunst, Macrae \& Turk, 2013). In one ownership study, Cunningham et al. (2008) asked participants to sort cards showing pictures of objects into self-owned and other-owned 
sets on the basis of a color cue (e.g., all cards with a red sticker belong to Participant A). Although the 'ownership' was clearly temporary, hypothetical and arbitrary in the sorting task, even this minimal level of self-association was sufficient to produce a robust memory advantage for the self-owned objects. Subsequent work has found similar preferential processing for stimuli presented simultaneously with a self-image or self-name (Turk et al., 2008), shapes associated with a self-label (Sui et al., 2012), and objects acted on by self (Ross et al., 2011). Taken together, these studies suggest that the SRE is not dependent on trait evaluation but can be driven by less abstract tasks that create an association between the self and external stimuli.

The usefulness of these non-evaluative paradigms lies in their ability to assess self-referential processing biases in the absence of abstract, elaborate, psychological self-knowledge that may be impaired in autism. Rather than relying on elaboration and organization by the self-knowledge framework (Klein \& Loftus, 1988; Klein \& Kihlstrom, 1986; Symons \& Johnston, 1997), low-level responses to self-cues are likely to drive the effects, particularly increases in attention to self-relevant stimuli. This reasoning is supported by both behavioral and neuroimaging studies, showing that cues of self-ownership elicit prioritizing attentional responses that ensure the selfrelevant information is preferentially processed (Bargh, 1982; Gray, Ambady, Lowenthal, \& Deldin, 2004; Sui, He, \& Humphreys, 2012; Turk, Brady-Van den Bos, Collard, Gillespie-Smith, Conway, \& Cunningham, 2013; Turk, van Bussel, Brebner, Toma, Krigolson, \& Handy, 2011; Turk, van Bussel, Waiter et al., 2011; Turk, van den Bos et al, 2010).

Developmental research supports the proposal that non-evaluative SRE paradigms allow self-referential processing biases to be explored in new populations. For example, Cunningham et al. (2013) used the ownership sorting paradigm to 
explore the SRE in early childhood, a stage at which the trait judgment paradigm is developmentally inappropriate. In this study, young children sorted toy-images into self-owned and other-owned sets, again based on color cues. A subsequent recognition memory test revealed that children aged as young as four years had better memory for objects encoded with reference to self. This study suggests that the ownership paradigm can offer a platform on which to build an understanding of selfprocessing in populations whose SRE performance is subject to mixed findings such as ASD.

One recent study has sought to initiate this line of research. Grisdale, Lind, Eacott, and Williams (2014) tested 16 adults with ASD and 16 typically developing adults using Cunningham et al.'s (2008) ownership task. They found that there was a significant memory advantage for self-owned items in the typically developing group, but not in the group with ASD. Additional analysis revealed a negative but nonsignificant relationship between the size of the ownership effect and self-reported ASD symptom severity (indicated by the Autism Spectrum Quotient - AQ; BaronCohen et al., 2001). Interestingly, in a separate experiment Grisdale et al. found that within a typically developing adult sample, the memory advantage for self-owned items was significantly correlated with scores on the AQ. Specifically, participants who showed more ASD traits had less of an ownership effect (i.e., a lower SRE).

Grisdale et al.'s findings suggest that there is scope to use ownership to explore self-processing in ASD in more depth, particularly with regards to variation within a heterogeneous ASD group. The current study seeks to apply this methodology earlier in development to examine the memorial impact of self- and other-ownership in groups of children with ASD and two comparison groups (CA group: matched for chronological age; VA group: matched for verbal age), and to 
explore the relationship between ownership biases in memory and sociocommunicative abilities, and autism severity.

We predict that use of the concrete, non-evaluative ownership paradigm will demonstrate an SRE (i.e., memory advantage for self-owned relative to other-owned items) across the groups. However, in line with previous research (e.g., Burrows et al., 2017; Lombardo et al., 2007) we predict that the magnitude of the self-memory advantage in the ASD group will be reduced relative to typically developing controls, and that it will be associated with levels of ASD characteristics (specifically higher levels of ASD symptoms and low levels of socio-communicative ability being associated with lower levels of ownership effect).

\section{Method}

\subsection{Participants}

A total of 66 children participated in the study. This sample comprised 22 children with a clinical diagnosis as being on the autistic spectrum (ASD group), 22 typically-developing children individually matched for chronological age (CA group), and 22 typically-developing children individually matched for verbal age (VA group; see Table 1). Verbal ability was assessed using the British Picture Vocabulary Scale (BPVS II; Dunn, Dunn, Whetton, \& Burley, 1997). Non-verbal ability (NVA) was assessed by the Raven's Coloured Progressive Matrices (RCPM; Raven, Raven, \& Court 1998). T-tests were carried out to check that the ASD group did not differ significantly in chronological age compared to the CA group $\mathrm{t}(42)=.020, \mathrm{p}=.984, d$ $=.01$, or verbal age compared to the VA group $\mathrm{t}(42)=.184, \mathrm{p}=.855, d=.06$. 
The children with autism were recruited from specialist ASD units attached to three mainstream schools and diagnosis was confirmed using medical records prior to testing. In addition school teachers identified children with sufficient verbal communication to follow task instructions and suitable for inclusion in the study. To assess levels of ASD trait presentation, teachers were asked to complete two questionnaires for each participant: the Asperger's Syndrome Diagnostic Scale (ASDS; Myles, Bock \& Simpson, 2001) and the Social Communication Questionnaire (SCQ; Rutter, Bailey, Berument, Lord \& Pickles, 2003). The group with ASD showed a wide range of symptom severity (range in ASDS - standardised scores from 37 to 128 ). 14 of the children with autism scored over 80 on the ASDS scale which indicates a probability of an Autism Spectrum Disorder, the overall group score was $(\mathrm{m}=85 ; \mathrm{SD}=26.4)$. The Social Communication Questionnaire (SCQ; Rutter et al. 2003) showed that the scores ranged from 1 to 17 , with 3 children in the ASD group obtaining a score over 15 (a score of 15 or over implies the presence of ASD) the overall group score was $(m=7 ; \mathrm{SD}=5.4)$. This indicates that despite these children manifesting high social and communicative abilities (as indicated by the SCQ), they still displayed high levels of behaviours and cognitive symptoms associated with autism as shown by the ASDS scores.

\subsection{Materials}

The set of picture cards consisted of 84 laminated images of highly familiar toys (e.g. Superman, lion, crayons) pictured on a $90 \mathrm{~mm}$ x $90 \mathrm{~mm}$ white background. Twenty-eight had a $10 \mathrm{~mm}$ orange border, 28 had a $10 \mathrm{~mm}$ grey border, and 28 were not used in the ownership task but were used as foils in the subsequent recognition 
task. The toys shown on the cards were divided into three equivalent lists, matched for toy type (e.g. cuddly toys, outdoor toys), stereotypic owner gender and syllabic length. Three sets of cards were created so that the use of the items as orangebordered, grey-bordered and foils for the recognition task could be counterbalanced across participants. The order of the cards within each set was randomized (by shuffling), but the sets were prearranged to ensure that each child sorted half of the cards that went into their basket, and half the cards that went into their partner's basket.

\subsection{Procedure}

Testing was carried out in school over two sessions. The ownership task and BPVS II were conducted in Session 1 and the RCPM was carried out in Session 2. Each child's classroom teacher was asked to complete the ASDS and SCQ measures in their own time.

For the ownership task children were taken in pairs to a quiet room within the school. Children were always paired with another child based on diagnostic group and gender (on one occasion one male and one female from the typical group had to 'stand in' with a new participant however their answers during this second participation were not recorded). In the room they were invited to sit side-by-side opposite the experimenter and had two baskets (one orange and one grey) placed in front of them. The children were asked to imagine that they owned the basket directly in front of them and any items that were placed inside this basket. 
Following the procedure used by Cunningham et al. (2013) the children were asked to take turns to put the cards into the appropriate basket, by matching the colour of a border around the card with the colour of the basket. The experimenter held up each card individually at an equal distance from each child, named the pictured toy, and handed the card to one of the children to sort. The child then put the card face down in the correct basket (either their own or the other child's). This design ensured that the children had to attend to items that went into both baskets, and that children encoded all the items in the context of ownership by one referent (i.e., self or other). They were asked not to talk during the sorting task.

Following the completion of the ownership task the experimenter took each child to a separate table for a surprise recognition memory test. To prevent the impact of the verbal cue serving as the trigger for recognition and to reduce the 'yes bias' (the tendency to answer "yes" to yes-no questions; Moriguchi, Okanda \& Itakura, 2008) all 84 un-bordered picture cards were laid out on a table (28 self-owned, 28 otherowned and 28 previously unseen). All children were separated (so that they could not observe their partner's performance in the recognition memory task) and individually asked to select any cards that they could remember from the sorting task. Children were told that they had not seen all of the cards so they needed to be careful in their selection. All of the cards that the child selected were given to the experimenter and put aside for later manual recording to guarantee that the child was not aware of whether they had selected correct or incorrect cards.

\section{Results}


Participants' proportionate hit rate (corrected for false alarm rate) was used as the dependent variable for the initial analysis. False alarm rates were low overall, with a mean of $5.95 \%$ of foils incorrectly selected during the memory test.

A mixed ANOVA was carried out with Ownership (Self, Other) as within subjects factor and Group membership (ASD, CA, VA) as between subjects factor. There was a significant main effect of Ownership on memory performance, $F(1,63)=$ 25.72, $p>.001, \eta_{p}{ }^{2}=.29$, showing that participants across the three groups remembered more self-owned items compared to other-owned. There was no significant effect of Group $F(2,63)=.232, p=.79, \eta_{p}{ }^{2}=.007$, however there was a significant interaction between Ownership and Group, $F(2,63)=4.03, p=.023, \eta_{p}{ }^{2}=$ .113 (see Figure 1).

\section{Figure 1 here}

Pairwise comparisons of the ownership effect for each group revealed significant a simple main effect of ownership for the ASD group $t(21)=4.00, p=.001, d$ $=.87$ for the CA group $t(21)=2.157, p=.043, d=.48$, and for the VA group $t(21)=2.306, p=.031, d=.70$. All groups showed higher memory for the self-owned items than for the other-owned items $\left(\right.$ Self; $\mathrm{M}_{\mathrm{ASD}}=.537, \mathrm{SD}_{\mathrm{ASD}}=.34 ; \mathrm{M}_{\mathrm{CA}}=.533$, $\mathrm{SD}_{\mathrm{CA}}=.24 ; \mathrm{M}_{\mathrm{VA}}=.531, \mathrm{SD}_{\mathrm{VA}}=.29:$ Other; $\mathrm{M}_{\mathrm{ASD}}=.367, \mathrm{SD}_{\mathrm{ASD}}=.38, \mathrm{M}_{\mathrm{CA}}=.471$, $\left.\mathrm{SD}_{\mathrm{CA}}=.27, \mathrm{M}_{\mathrm{VA}}=.477, \mathrm{SD}_{\mathrm{VA}}=.24\right)$. One-way ANOVAs showed no significant difference in either self-owned item memory $\left(F(2,63)=0.268, p=.766, \eta_{p}{ }^{2}=.008\right)$ or other-owned item memory $\left(F(2,63)=0.719, p=.491, \eta_{p}^{2}=.022\right)$ across groups. To determine the locus of the group by ownership interaction, we carried out a further one-way ANOVA using the recognition advantage for self-owned items (i.e., proportion of self-owned items minus proportion of other-owned item correctly 
recognized) as the dependent variable, to explore more closely the difference between self- and other-owned item memory. This analysis revealed a significant effect of group $F(2,65)=4.026, p=.023, \eta_{p}{ }^{2}=.113$. Post-hoc tests demonstrated that there was a larger self-advantage in the ASD group compared to both the $\mathrm{CA}(p=.021, d=.45)$ and VA groups $(p=.014, d=.47)$. The CA and VA groups did not differ significantly from one another $(p=.861, d=.39)$.

The unexpected finding that participants in the ASD group had a greater memory advantage for self-owned items than the two comparison groups prompted an analysis of patterns within the group of participants with ASD. Correlations between self-advantage score and the measures of individual difference were calculated. There was a significant negative association between self-advantage score and both measures of ASD trait severity (SCQ $r=-0.507, p=0.016$; ASDS scores $r=-.608, p$ $=.003)$. This suggests that the more autistic traits participants showed, the lower the self-advantage, a pattern that replicates previous work (Grisdale et al., 2014) but initially seems at odds with the heightened self-advantage of participants in the ASD group in the current study. Examination of memory for self-owned and other-owned items within the ASD group provides an explanation. As can be seen in Figure 2, these data suggest that the ASD group's high self-owned memory advantage is driven by ASD participants with milder symptoms, and increased autistic trait level extinguishes the self-owned bias.

This pattern was examined by dividing ASD participants into mild $(N=11)$ and severe $(N=11)$ symptoms groups on the basis of an ASDS score median split. Comparison of the self-owned and other-owned scores separately showed no reliable difference between the mild and severe symptom groups (self-owned items: $F(1,20)=$ $.718, p=.407, \eta_{p}{ }^{2}=.035$; other-owned items: $\left.F(1,20)=1.251, p=.277, \eta_{p}{ }^{2}=.059\right)$. 
However, within-group contrasts did reveal a divergent pattern. The difference between memory for self-owned and other-owned items was highly reliable among the children with mild ASD symptoms $(t(10)=4.435, p<.001, d=1.501)$, but this trend did not reach significance in children with severe ASD symptoms $(t(10)=$ $1.927, p=.083, d=.729)$. These patterns should be treated cautiously given the low numbers in each group, but nonetheless show an interesting correspondence with the pattern indicated by the correlations reported above, with milder symptoms being associated with a stronger self-reference effect.

\section{Figure 2 here}

\section{Discussion}

The current study applied an ownership paradigm to assess the effects of selfprocessing biases on memory in children with ASD. Children with ASD showed a significant self-bias, recognizing a higher proportion of self-owned than other-owned items. Children in the typically developing verbal- and chronological- age-matched comparison group also showed this 'ownership effect' in memory (Cunningham et al., 2008). An unexpected finding was that the magnitude of this memory bias was actually greater in the ASD group than in the typically-developing comparison groups. This increased SRE magnitude was driven by children in the ASD group who had lower levels of ASD traits, as there was a significant negative correlation between symptom severity and self-bias, and a strong, reliable self-bias only those children in the ASD group who had milder symptoms. This complex pattern supports our main experimental predictions, but offers some insight into the way in which selfprocessing biases might vary in children with different degrees of ASD severity. 
We predicted that children with ASD would show a significant ownership effect because self-associations created through ownership can evoke self-processing biases without relying on abstract character knowledge, unlike the standard SRE trait evaluation task (Cunningham et al., 2008). We reasoned that previous SRE research with children and adults with ASD using this task (Henderson et al., 2009; Toichi et al., 2002) may have underestimated the prevalence of SREs because of the inherent abstract nature of the trait adjective task. The group-level data support this claim, with ownership effects in memory emerging in the ASD group and both comparison groups. Indeed, the ASD group actually showed a higher SRE relative to the comparison groups. Although this is contrary to previous studies in which SRE has been lower in ASD compared to controls (Burrows et al., 2016; Grisdale et al., 2014; Henderson et al., 2009), it is consistent with the abundance of ASD research suggesting that autistic individuals pay less attention to other people than neurotypical comparison groups (Hobson, 1984; Lord, Rutter, \& Le Couteur, 1994; Werner, Dawson, Osterling, \& Dinno, 2000). If there is egocentricity and reduced interest in others, and by extension, others' belongings, then this should increase SREs by exacerbating the difference between attention paid to self- and other-referent stimuli.

The emergence of a strong SRE in a group of children with ASD appears inconsistent with the absent self theory (Frith \& Happé, 1999; Frith, 2003), in which disrupted self-processing is argued to impair the ability to understand other perspectives (simulation theory - Goldman, 2006). The group-level data are therefore more consistent with the idea that a lack of attention or interest in other people drives the social processing impairments associated with ASD (Baron-Cohen, Lombardo, \& Tager-Flusberg, 2013). However, the sensitivity of the ownership task to self-memory bias allowed us to examine individual differences between children who show mild 
versus severe levels of ASD symptoms. A negative association was found between ASD symptom severity (as indicated by the ASDS and the SCQ) and self-memory bias. Further, when children in the ASD group were divided into those with mild v. severe symptoms, a significant ownership effect only emerged in those with mild symptoms. These findings suggest that the high ownership effect in the ASD group as a whole is driven by participants with relatively mild symptoms. The more severe the level of ASD traits, the lower the self-memory bias. This pattern is more consistent with the research which shows an absence (Henderson et al., 2009; Toichi et al., 2002) or attenuation (Lombardo et al., 2007) of the SRE in people with ASD, and with Grisdale et al.'s finding that the magnitude of the SRE decreases with increasing socio-communicative difficulties (Grisdale et al., 2014; Henderson et al., 2009). Thus we suggest that for individuals who have a high level of ASD traits and low sociocommunicative ability, there may be impaired self-functioning (an absent self).

In sum, the data patterns suggest that in neurotypical participants, there is a priorotisation of self over others that gives rise to SREs such as the ownership effect, but attention can also be diverted to others where appropriate; in mildly autistic children, there is likely to be a self bias that is exacerbated because attention tends not to be diverted to others; in severely autistic children, there may be no self-bias in the first place. An interesting aspect of the magnitude of SRE in participants with ASD (which is tentatively suggested), is that the emphasized 'self' and 'other' performance in those who have less severe ASD may be associated with a lack of attention shifting (Rinehart, Bradshaw, Moss \& Brereton, 2001; Courchesne, Townsend, \& Akshoomoff 1994) and cognitive flexibility (for a review see Geurts et al., 2009). The impaired ability to consider 'others' or 'another's perspective' may be linked to an inability to disengage (de Vries \& Geurts 2012) from 'self'. Further research is 
therefore required to examine potential links not only between symptom and social abilities (such as those in the current paper) but also cognitive profiles (i.e. cognitive flexibility).

The complexity of the relationship that we found between the ownership effect and autistic traits casts some light on previous findings concerning the level of selfreference effect found in ASD samples. In particular, the mixed findings regarding the strength of SRE within ASD samples may be a result of varying levels of ASD trait severity within the tested groups. The current study suggests that an SRE is more likely to be found if a group of ASD-diagnosed participants who showed mild symptoms were tested, whereas an SRE would be less likely to emerge in a sample consisting of participants with a very high level of ASD traits. This is currently a speculative prediction, but we strongly suggest that measures of autistic traits (e.g., socio-communicative processing) in future analyses of self-referencing so that the incidence of self-processing biases in ASD can be more fully understood.

The current findings also have methodological implications. They suggest that the use of a concrete, object-based measure of self-memory bias can highlight SRE abilities and differences in a group with complex needs (see also Cunningham et al., 2014; Grisdale et al., 2014). The ownership task requires more concrete self-item associations and the results of the current study provide evidence that this task is sensitive to self-bias within a group of ASD-diagnosed children evidenced by them showing an SRE. Groups of individuals with ASD display varied levels of cognitive and verbal abilities, which interact in complex ways (Rice, Moriuchi, Jones, \& Klin, 2012), so the appropriateness of standard paradigms must be a consideration. 


\section{Conclusions}

The current study indicates that children with ASD can show an intact SRE when an appropriate paradigm like the ownership task is used. However, this effect is dependent on symptom severity: self-bias was reduced in children who showed higher levels of ASD traits and low socio-communicative ability, but increased in children with lower levels. These findings explain previous mixed findings by suggesting that self processing biases are intact in some children with ASD, perhaps as a result of very low attention to others, but reduced in others, perhaps due to an 'absent self'. The data are consistent with suggestions that self-processing may be anchored within the social difficulties observed at the more severe end of the autistic spectrum. 


\section{References}

Adolphs, R., Sears, L., \& Piven, J., (2001). Abnormal processing of social information from faces in autism. Journal of Cognitive Neuroscience, 13, 232-240.

American Psychiatric Association (2013). Diagnostic and statistical manual of mental disorders (DSM-V). Washington, DC: American Psychiatric Association.

Asperger, H. (1944). Die autistischen psychopathen im kindersalter. Archiv fur Psychiatrie und Nervenkrankheiten, 117, 76-136.

Bargh, J. A. (1982). Attention and automaticity in the processing of self-relevant information. Journal of Personality and Social Psychology, 43, 425-436.

Baron-Cohen, S. (1988). Social and pragmatic deficits in autism: Cognitive or affective? Journal of Autism and Developmental Disorders, 18, 379-402.

Baron-Cohen, S. (1999). The extreme male brain theory of autism. In H. TagerFlusberg (Ed.), Neurodevelopmental disorders. Boston: MIT Press/Bradford Books. Baron-Cohen, S., Leslie, A. M. \& Frith, U. (1985). Does the autistic child have a 'theory of mind'? Cognition, 21, 37-46.

Baron-Cohen, S., Lombardo, M., \& Tager-Flusberg, H. (Eds.). (2013).Understanding other minds: Perspectives from developmental social neuroscience. OUP Oxford.

Baron-Cohen, S., Wheelwright, S., Skinner, R., Martin, J., \& Clubley, E. (2001). The autism-spectrum quotient (AQ): Evidence from Asperger syndrome/high functioning autism, males and females, scientists and mathematicians. Journal of Autism and Developmental Disorders, 31, (1), 5-17. 
Bauminger, N., Shulman, C., \& Agam, G. (2003). Peer interaction and loneliness in high-functioning children with autism. Journal of Autism and Developmental Disorders, 33(5), 489-507.

Bird, G., Silani, G., Brindley, R., White, S., Frith, U., \& Singer, T. (2010). Empathic brain responses in insula are modulated by levels of alexithymia but not autism. Brain, 133, (5), 1515-1525.

Burrows, C. A., Usher, L. V., Mundy, P. C., \& Henderson, H. A. (2017). The salience of the self: Self-referential processing and internalizing problems in children and adolescents with autism spectrum disorder. Autism Research, 10(5), 949-960.

Conway, M. A., \& Dewhurst, S. A. (1995). The self and recollective experience. Applied Cognitive Psychology, 9, 1-19.

Crane, L. \& Goddard, L. (2008). Episodic and semantic autobiographical memory in adults with autism spectrum disorders. Journal of Autism and Developmental Disorders, 38, 498-506.

Cunningham, S. J., Brebner, J. L., Quinn, F., \& Turk, D. J. (2014). The self-reference effect on memory in early childhood. Child Development, 85, 808-823. doi:10.1111/cdev.12144.

Cunningham, S. J., Turk, D. J., MacDonald, L. M., \&Macrae, C. N. (2008). Yours or mine? Ownership and memory. Consciousness and Cognition, 17, 312-318. doi:10.1016/j.concog.2007.04.003

Dawson, G., \& McKissick, F. C. (1984). Self-recognition in autistic children. Journal of Autism and Developmental Disorders, 14, (4), 383-394. 
Dunphy-Lelii, S. \& Wellman, H. M. (2012). Delayed self-recognition in autism: A unique difficulty? Research in Autism Spectrum Disorders, 6, 212-223.

Frith, U. (2003). Autism: Explaining the Enigma (2 ${ }^{\text {nd }}$ Edition). Oxford: Blackwell.

Frith, U., \& Happé, F. (1999). Theory of mind and self-consciousness: What is it like to be autistic? Mind \& Language, 14, (1), 1-22.

Goldman, A. I. (2006). Simulating minds: The philosophy, psychology, and neuroscience of mind reading. New York: Oxford University Press.

Gray, H. M., Ambady, N., Lowenthal, W. T., \& Deldin,, (2004). P300 as an index of attention to selfrelevant stimuli. Experimental Social Psychology, 40, 216-224. doi:10.1016/S0022-1031(03)00092-1

Grisdale, E., Lind, S. E., Eacott, M. J., \& Williams, D. M. (2014). Self-referential memory in autism spectrum disorder and typical development: Exploring the ownership effect. Consciousness and Cognition, 30, 133-141.

Gutchess, A. H., Sokal, R., Coleman, J. A., Gotthilf, G., Grewal, L., \& Rosa, N. (2015) Self-referential memory with age: Evidence for common and distinct encoding strategies. Brain Research, 1612, 118-127.

Harter, S. (1990). Issues in the assessment of the self-concept of children and adolescents. In S. M. LaGreca (ed.), Through the Eyes of the Child: Obtaining Selfreports from Children and Adolescents: 292-325. Boston: Allyn \& Bacon.

Harter, S., \& Pike, R. (1984). The pictorial scale of perceived competence and social acceptance for young children. Child Development, 1969-1982. 
Heerey, E. A., Keltner, D., \& Capps, L. M. (2003). Making sense of self-conscious emotion: Linking theory of mind and emotion in children with autism. Emotion, 3, 394-400.

Henderson, H. A., Zahka, N. E., Kojkowski, N.M., Inge, A. P., Schwartz, C. B., Hileman, C. M., Coman, D., C. \& Mundy, P., C. (2009). Self-Referenced memory, social cognition, and symptom presentation in autism. Journal of Child Psychology and Psychiatry, 50 (7), 853-861.

Hobson, R.P. (1984) Early childhood autism and the question of egocentrism. Journal of Autism and Developmental Disorders, 14, 85-104.

Kasari, C., Sigman, M. D., Baumgartner, P. \& Stipek, D. J. (2006). Pride and mastery in children with autism. Journal of Child Psychology and Psychiatry, 34, 353-362.

Klein, S. B., \& Kihlstrom, J. F. (1986). Elaboration, organization, and the selfreference effect in memory. Journal of Experimental Psychology: General, 115, 2638. doi:10.1037/0096-3445.115.1.26

Klein, S. B., \& Loftus, E. M. (1988). The nature of self-referent encoding: The contribution of elaborative and organisational processes. Journal of Personality and Social Psychology, 55, 5-11. doi:10.1037/0022-3514.55.1.5

Lee, A., Hobson, R. P., \& Chiat, S. (1994). I, you, me and autism: An experimental study. Journal of Autism and Developmental Disorders, 24 (2), 155-176.

Leekam, S., \& Perner, J. (1991). Does the autistic child have a meta-representational deficit? Cognition, 40, 203-218. 
Lind, S. E. (2010). Memory and the self in autism: A review and theoretical framework. Autism, 14(5), 430-456.

Lind, S. E. \& Bowler, D. M. (2009). Delayed self-recognition in children with autism spectrum disorder. Journal of Autism and Developmental Disorders, 39, 643-650.

Lombardo, M. V., Chakrabarti, B., Bullmore, E. T., Sadek, S. A., Pasco, G., Wheelwright, S. J., Suckling, J., MRC AIMS Consortium, \& Baron-Cohen, S. (2010). Atypical neural self-representation in autism. Brain, 133, 611-24.

Lombardo, M. V., Barnes, J. L., Wheelwright, S.J., \& Baron-Cohen, S. (2007). Selfreferential cognition and empathy in autism. PLoS One, 2, e883.

Lord, C., Rutter, M., \& Le Couteur, A. (1994). Autism Diagnostic Interview-Revised: a revised version of a diagnostic interview for caregivers of individuals with possible pervasive developmental disorders. Journal of Autism and Developmental Disorders, 24(5), 659-685.

Millward, C., Powell, S., Messer, D., \& Jordon, R. (2000). Recall for self and other in autism: Children's memory for events experienced by themselves and their peers. Journal of Autism and Developmental Disorders, 30 (1), 15-28.

Moriguchi, Y., Okanda, M. \& Ikatura, S. (2008). Young children's yes bias: How does it relate to verbal ability, inhibitory control, and theory of mind? First Language, $28(4), 431-442$.

Mundy, P. (2003). Annotation: The neural basis of social impairments in autism: The role of the dorsal medial-frontal cortex and anterior cingulated system. Journal of Child Psychology and Psychiatry, 44, 793-809. 
Munesue, T., Ono, Y., Mutoh, K., Shimoda, K., Nakatani, H., \& Kikuchi, M. (2008). High prevalence of bipolar disorder comorbidity in adolescents and young adults with high-functioning autism spectrum disorder: a preliminary study of 44 outpatients. Journal of Affective Disorders, 111(2), 170-175.

Neuman, C. J., \& Hill, S. (1978). Self-recognition and stimulus preference in autistic children. Developmental Psychobiology, 11, (6), 571-578.

Oberman, L. M. \& Ramachandran, V. S. (2007) The simulating social mind: The role of the mirror neuron system and simulation in the social and communicative deficits of autism spectrum disorders. Psychological Bulletin, 133, 310-327.

Philip, R. C. M., Whalley, H. C., Stanfield, A. C., Sprengelmeyer, R., Santos, I. M., Young, A. W., Atkinson, A. P., Calder, A. J., Johnstone, E. C., Lawrie, S. M., \& Hall, J. (2010). Deficits in facial, body movement and vocal emotional processing in autism spectrum disorders. Psychological Medicine, 40, 1919-1929.

Povinelli, D. J. (2001). The self: Elevated in consciousness and extended in time. In C. Moore \& K. Lemmon (Eds.), The self in time: Developmental Perspectives (pp. 75-95).

Robins, R. W., Trzesniewski, K. H., Tracy, J. L., Gosling, S. D., \& Potter, J. (2002). Global self-esteem across the life span. Psychology and Aging, 17 (3), 423.

Rogers, T. B., Kuiper, N. A., \& Kirker, W. S. (1977). Self-reference and the encoding of personal information. Journal of Personality and Social Psychology, 35, 677-688. doi:10.1037/0022-3514.35.9.677

Ross, J., Anderson, J. R., \& Campbell, R. N. (2011). I remember me: Mnemonic selfreference effects in preschool children. Monographs of the Society for Research in 
Child Development, 76 (3), 1-102.

Rutter, M., Bailey, A., Berument, S. K., Lord, C., \& Pickles, A. (2003). Social communication questionnaire (SCQ). Los Angeles, CA: Western Psychological Services.

Silani, G., Bird, G., Brindley, R., Singer, T., Frith, C., \& Frith, U. (2008). Levels of emotional awareness and autism: An fMRI study. Social Neuroscience, 3, (2), 97-112.

Spiker, D., \& Ricks, M. (1984). Visual self-recognition in autistic children:

Developmental relationships. Child Development, 55, (1), 214-225.

Sui, J., He, X. \& Humphreys, G.W. (2012) Perceptual effects of social salience:

Evidence from self-prioritization effects on perceptual matching. Journal of Experimental Psychology: Human Perception and Performance, 38, 1105-1117.

Sui, J., \& Zhu, Y. (2005). Five-year-olds can show the self-reference advantage. International Journal of Behavioral Development, 29, 382-387.

doi:10.1080/01650250500172673

Symons, C. S., \& Johnson, B. T. (1997). The self-reference effect in memory: A meta-analysis. Psychological Bulletin, 121, 371-394. doi:10.1037/0033-

2909.121.3.371

Toichi, M., Kamio, Y, Okada, T., Sakihama, M., Youngstorm, E., A., Findling, R., L., Kokichi, Y. (2002). A Lack of Self-Consciousness in Autism. American Journal of Psychiatry, 159 (8), 1422-1424.

Turk, D. J. Brady-Van den Bos, M., Collard, P., Gillespie-Smith, K., Conway, M. A., \& Cunningham, S. J., (2013). Divided attention selectively impairs memory for self- 
relevant information. Memory and Cognition, 41, 503-510. doi: 10.3758/s13421-0120279-0.

Turk, D. J., Cunningham, S. J. \& Macrae, C. N. (2008). Self-memory biases in explicit and incidental encoding of trait adjectives. Consciousness and Cognition, 17, 1040-1045. doi: 10.1016/j.concog.2008.02.004.

Turk, D. J., van Bussel, K., Brebner, J. L., Toma, A., Krigolson, O., \& Handy, T. C. (2011). When IT becomes MINE: Attentional biases triggered by object ownership. Journal of Cognitive Neuroscience, 23, 3725-3733. doi:10.1162/jocn_a_00101

Turk, D. J., van Bussel, K., Waiter G. D., Macrae, C. N. (2011) Mine and me: Exploring the neural basis of object ownership. Journal of Cognitive Neuroscience, $23,3657-3668$.

Uddin, L. Q., Davies, M. S., Scott, A. A., Zaidel, E., Bookheimer, S. Y., \& Iacoboni, M. (2008). Neural basis of self and other representation in autism: an FMRI study of self-face recognition. PLoS ONE, 3, (10): e3526.

Van den Bos, M., Cunningham, S. J., \& Turk, D. J. (2010). Mine to remember: The effects of minimal ownership on remembering and knowing. Quarterly Journal of Experimental Psychology, 63, 1065-1071. doi: 10.1080/17470211003770938.

Wainscot, J. J., Naylor, P., Sutcliffe, P., Tantam, D., \& Williams, J. V. (2008). Relationships with peers and use of the school environment of mainstream secondary school pupils with Asperger Syndrome (High-Functioning Autism): A case-control study. International Journal of Psychology and Psychological Therapy, 8(1), 25-38. 
Werner, E., Dawson, G., Osterling, J., \& Dinno, N. (2000). Brief report: Recognition of autism spectrum disorder before one year of age: A retrospective study based on home videotapes. Journal of Autism and Developmental Disorders, 30(2), 157-162.

White, S. W., \& Roberson-Nay, R. (2009). Anxiety, social deficits, and loneliness in youth with autism spectrum disorders. Journal of Autism and Developmental Disorders, 39(7), 1006-101. 
Table 1: Participant details for children with autism and their typically developing comparison groups (standard deviation within parenthesis)

\begin{tabular}{|l|c|c|c|c|c|}
\hline Group & $\boldsymbol{N}$ & Gender Ratio & CA & VA $^{\text {ii }}$ & \\
\hline ASD & & males:females & & \\
\hline Chronological age-matched (CA) & 22 & $16: 6$ & 12.0 years (3.1) & 11.1 years (3.0) & $29(7)$ \\
\hline Verbal ability age-matched (VA) & 22 & $13: 9$ & 10.5 years (3.6) & 9.5 years (3.3) & $25(6)$ \\
\hline
\end{tabular}

i Chronological age provided in years and full months. Standard deviation provided in full months in parenthesis.

ii Verbal ability is calculated using the mean raw score from the British Picture Vocabulary Scale standard deviation in parenthesis.

iii Nonverbal ability is provided as mean scores on the Ravens Coloured Progressive Matrices task (max. score 36) standard deviation in parenthesis. 
Figure 1:

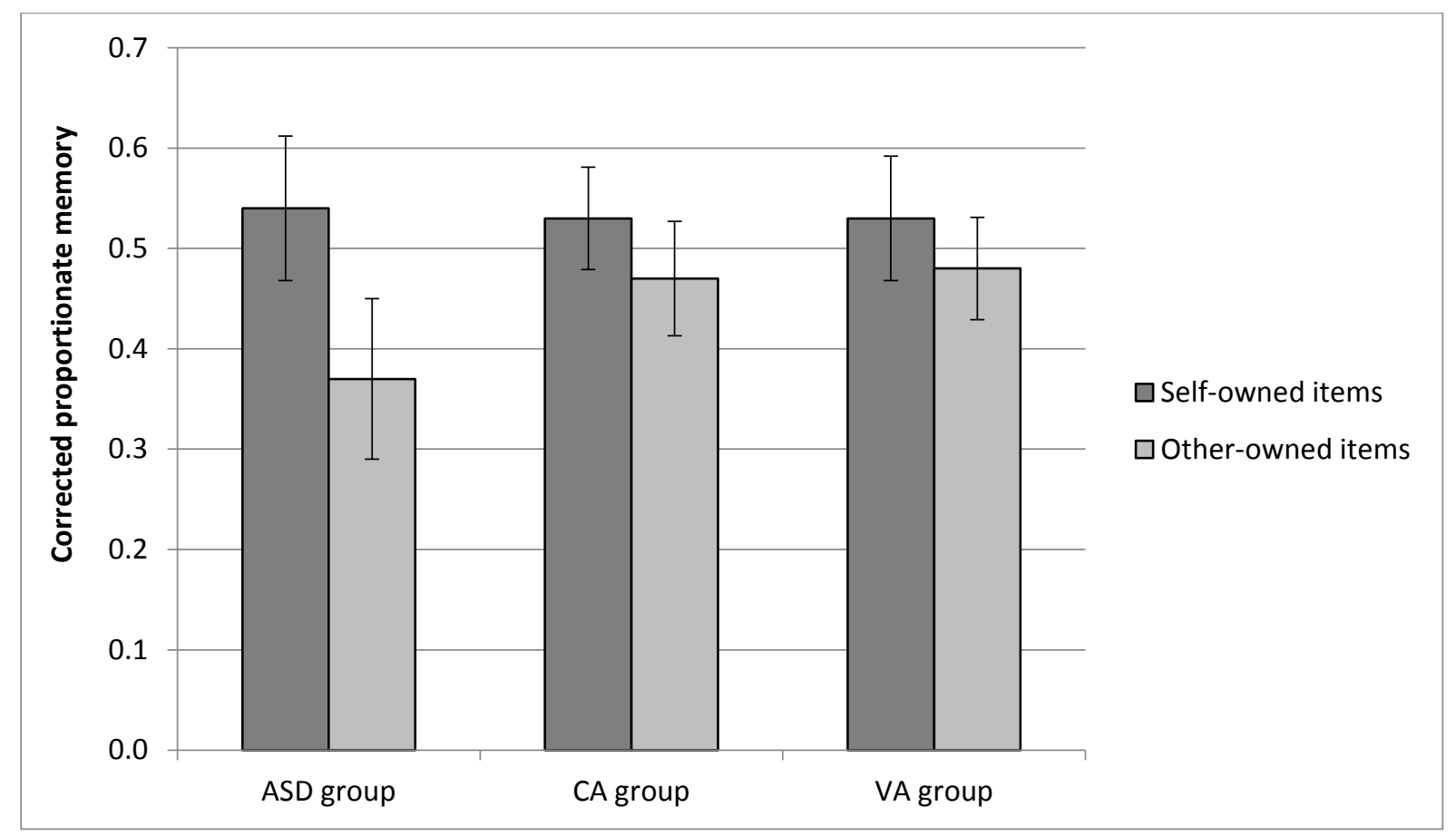


Figure 2: Scatterplot showing the relationship between SCQ scores (Panel A)/ASDS scores (Panel B) and the recognition advantage for self-owned items (i.e., proportion of self-owned items minus proportion of other-owned item correctly recognized) in the ASD group only.

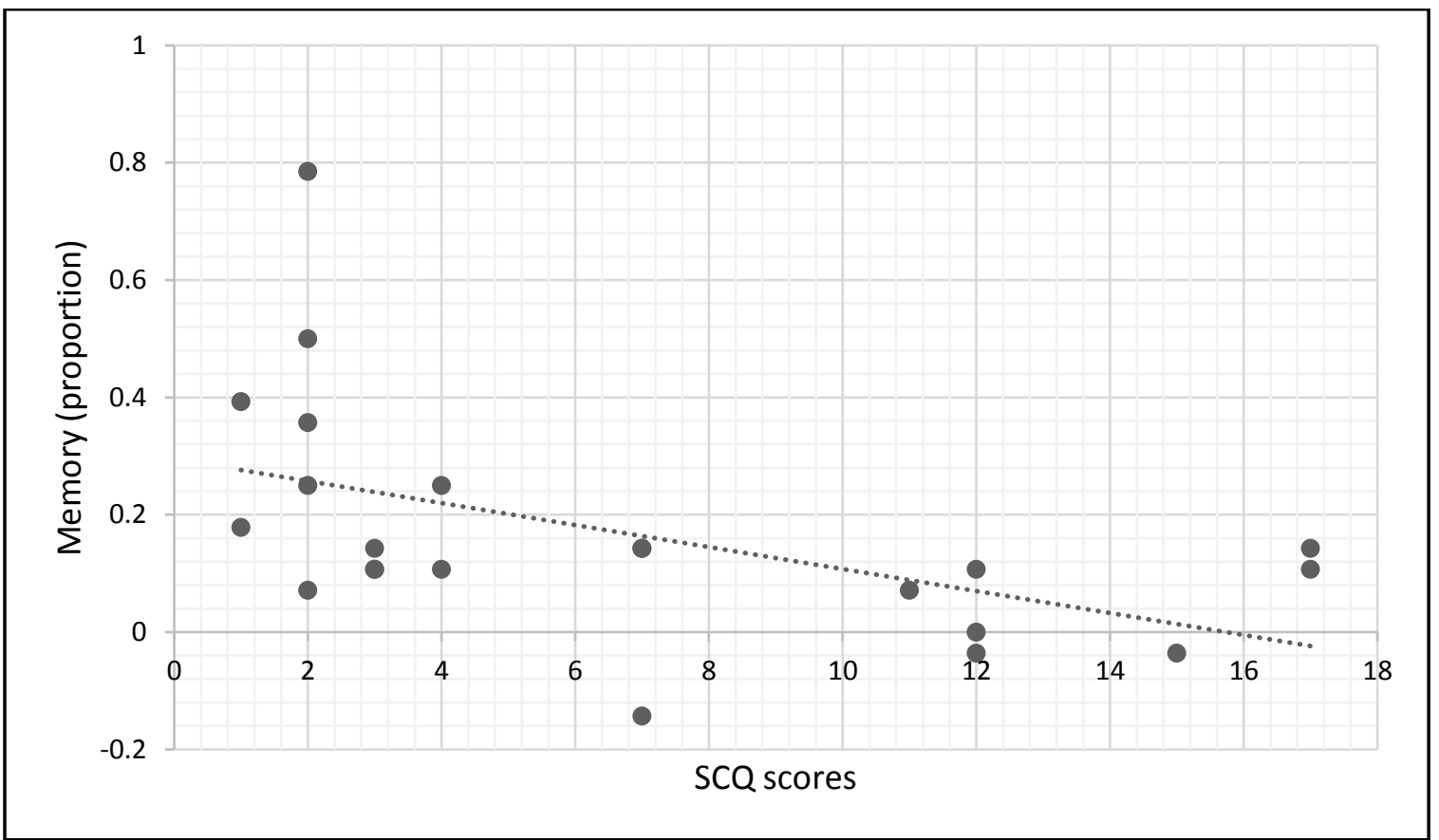

Panel A

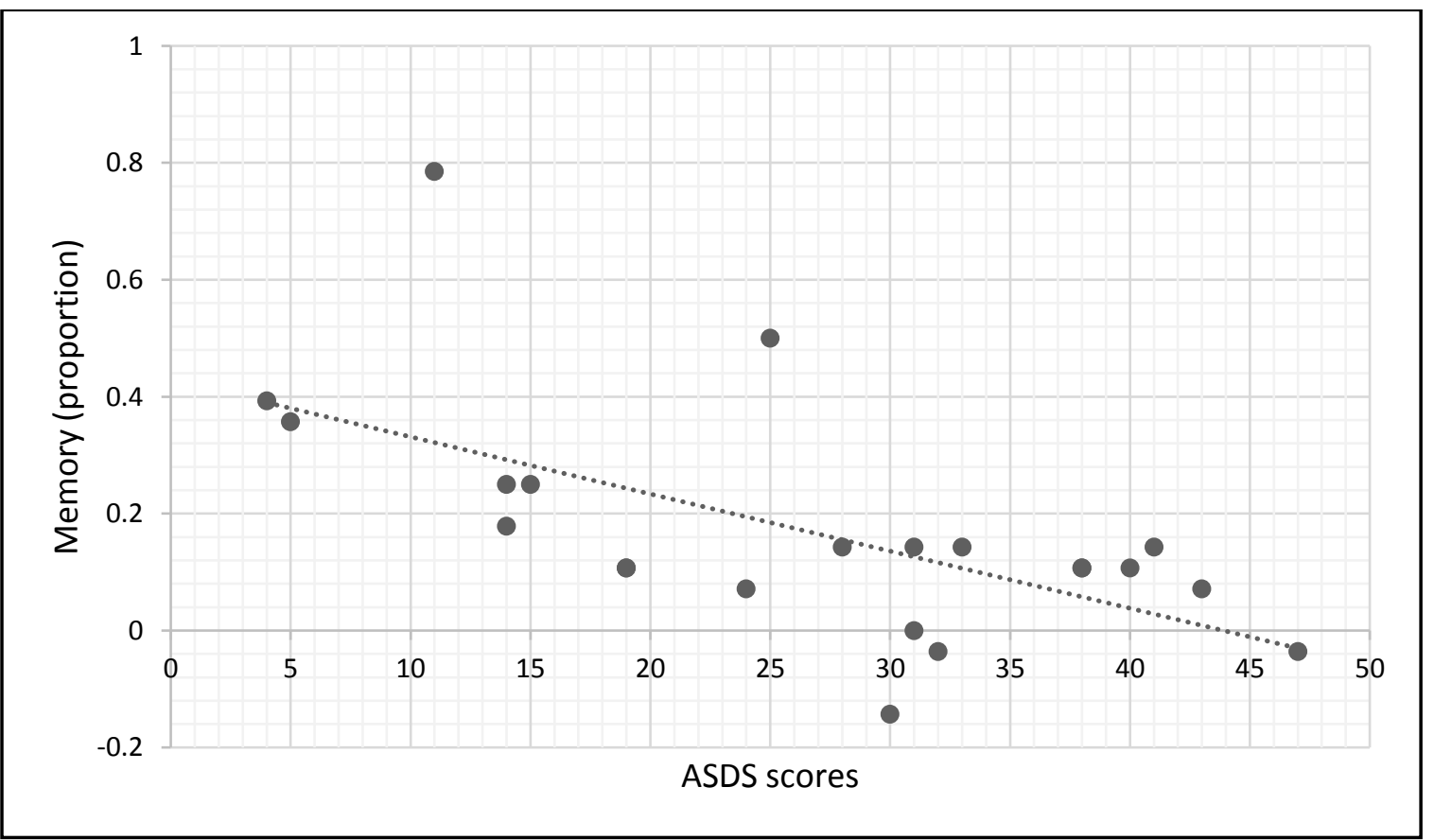

Panel B 
